\title{
In Search of Truthful Knowledge Through an Integrated Research Practice in the 5th Space-Time Dimension -A Monistic View
}

\author{
Norbert E. Haydam \\ Cape Peninsula University of \\ Technology, Cape Town, \\ South Africa
}

\author{
André Slabbert \\ Claremont, South Africa
}

\author{
Ernst A. Uken \\ Yaounde University of Cameroon, \\ Yaounde, Cameroon
}

\begin{abstract}
The paper draws on the key postulate of oneness (monism) and questions the objectivity, rationality and truthfulness of scientific inquiry in the social sciences. The study is theoretical by nature and follows the metascientific epistemic model of inquiry using a non-experimental conceptual historical inductive research design. In reconciling the physical with the metaphysical worlds, the paper draws on works of Ouspensky's six dimensional space-time universe and concludes that all is mind and the physical dualistic reality as per Quantum Mechanics is nothing but emptiness. By analysing the so-called five dimensional space-time universe, the authors then propose the inclusion of the metaphysical research design, which will augment the existing research designs (i.e., exploratory, descriptive, and causal) and enable scientists to come closer to truthful knowledge.
\end{abstract}

Keywords: truthful knowledge, fifth space-time dimension, research practice, metaphysical research design, Tarot, Ouspensky, Quantum Mechanics, monism

\section{Background}

The overriding point of departure and goal of the epistemic imperative in science are the search or quest for truthful knowledge (Mouton, 2006, pp. 17, 28-30). In this regard, knowledge is claimed to be truthful or valid (or at least plausible) if there is enough evidence to support the claims made by scientists. Thus, truth as an absolute notion should not be seen as a literal representation of reality, but rather as a commitment to an ideal and a goal to be pursued within a regulatory idealistic scientific framework. All interpretations of scientists are therefore only approximations of the truth at any given point in time expressed in varying degrees of the truth (the "ideal") by substituting terms such as "validity" and "goodness of fit" for approximations of the truth.

From here the scientific community judges why a specific claim or hypothesis about the truth should be accepted or rejected. This assessment is referred to as the rationality of science and is usually done by a group of experts which jointly scrutinises and confers on a "collective judgment" via consensus and accepts the most

Norbert E. Haydam, Ph.D., Faculty of Business and Management Sciences, Department of Marketing, Cape Peninsula University of Technology.

André Slabbert, Professor, Retired Academic, Claremont.

Ernst A. Uken, Professor, African Institute of Mathematical Sciences, Yaounde University of Cameroon. 
plausible claim to reality given the available evidence regarding the new treatise (Babbie \& Mouton, 2009, pp. 10-11). In its purest sense, rationality is impossible as clear and explicit rules in terms of the judgment to be done are lacking. The implication of this is that one's ability to act as a rational agent is limited by the scope of one's expertise (Garbers, 1996, p. 30).

Finally, regarding the nature and structure of the practice of science, it is given that only objective evidence can constitute the best estimates of the truth to make rational assessments of knowledge claims. Objectivity here is linked to the specific research procedures and methods and the methodological paradigm used (Babbie \& Mouton, 2009, pp. 11-12).

Babbie and Mouton (2009, p. 12) summarise the relationship between truth (as an epistemological criterion), rationality (sociological criterion) and objectivity (methodological criterion) as follows:

"The systematic and rigorous search for objective evidence — using objective methods and techniques—increases the likelihood of making rational judgments in the process of scientific inquiry. Beliefs that we hold are based of such judgements provide us with the best estimates of the truth. Stated differently, those beliefs which the scientific community accepts as reasonable (given the evidence), represent the most truthful claims about reality".

However, although not pertinently noticed in the social science sphere, the emergence of Quantum Physics at the turn of the twentieth century changed the way scientists look at reality altogether. Quantum Physics not only attacked one or two conclusions about classical physics, but it completely replaced the very cornerstone and foundation on which the whole edifice of the Newtonian reality was based (Wilber, 1993, p. 24). In this regard, Quantum Mechanics also calls scientists in the social sphere of research to re-examine their engagement as to what is currently perceived as objectivity, rationality, and truthful knowledge. The paper explores this possibility.

\section{Problem Statement}

The nature of reality as it manifested itself in the new Quantum Physics changed irrevocably the dimensions of what constituted objectivity in science with Heisenberg's Uncertainty Principle in 1927 (Boikes \& Edelson, 1978). His formulations were (and still are) so severe that it marked the end of Classical Theory (Wilber, 1993, p. 24).

In his first formulation, Heisenberg postulated the uncertainty principle to be (Hilgevoord \& Uffink, 2006, p. 1):

$$
\delta p \delta q \sim h
$$

In this formula (1), the matrices $\delta q$ and $\delta q$ represent the precision to which $q$, i.e., the wavelength of light is known, i.e., $\delta q$ being the statistical mean error of $q$, and $\delta p$ is the precision of the determinable discontinuous change of $p$ in the Compton Effect respectively. Uncertainty according to Heisenberg is then defined in terms of its statistical property of the location of the electron expressed by a mean error $(\delta q)$ and secondly as a restriction to simultaneously measure two physical properties of a particle, i.e., momentum $(p)$ and location $(q)$ (Arévalo Aguilar, García Quijas, \& Robledo-Sanchez, 2012, pp. 67-68).

Regarding the latter, the uncertainty principle asserts that one cannot assign exact value to the position and momentum of a physical system for it creates a disturbance on an observable particle when measured (Arévalo Aguilar et al., 2012, p. 67). Heisenberg found that in measuring the position of an electron using light of a very short wave length ( $\gamma$-rays) the Compton Effect cannot be ignored as the interaction of the 
electron and the illuminating light can be seen as a collision of at least one photon with one electron. The electron suffers recoil and its momentum is disturbed which is represented by a shift from $|p j-p i|$ (Hilgevoord \& Uffink, 2006, p. 3):

$$
|p j-p i| \delta q \sim h i
$$

From the formula (2), the position of the particle $(\delta q)$ is accurately known, but its momentum has changed, albeit arbitrarily small (Hilgevoord \& Uffink, 2006, p. 3). It was the startling conclusion that on a subatomic level, any observation disturbs reality. In some mysterious way, the subject and the object were intimately connected. Wilber (1993, p. 23) stresses the importance of this discovery:

"Objective measurement and verification could no longer be the mark of absolute reality, because the measured object could never be completely separated from the measuring subject - the measured and the measurer, the verified and the verifier, at this level, are one and the same".

This meant that Heisenberg's uncertainty principle established the universe indeterminate on its most basic level and consequently no exact cause and effect relationship could be ascertained. It was the realisation that the conscious observer directly influenced what was being observed (Wilber, 1993, p. 26). Given Heisenberg's uncertainty postulate, Quantum Mechanics therefore not only proclaim a world of oneness but categorically rejects objectivity - the very cornerstone on which truthful scientific knowledge is based.

In the second instance, for knowledge to be regarded as scientific it must be based on specific, verifiable and measureable fact or evidence (Bless, Higson-Smith, \& Kagee, 2008, pp. 14-16). However, accepting a monistic worldview of Quantum Mechanics through Heisenberg's Uncertainty Principle, it can be argued that the (conscious) rational reality and the (unconscious) non-rational are not separate, but one. Wilber (1993, p. 27) uses the analogy of a body to argue the concept of oneness. He argues that it was as if mankind were given two pictures of the body (which represents the wholeness and oneness of truthful knowledge or reality), namely the front (say the rational) and the back, i.e., the non-rational view of reality. Science over the years has been over-emphasising the front part of the body as truthful knowledge and has pleaded partial to total ignorance of the non-rational view in its search for its reality. Wilber (2000, p. 21) highlights the consequences to this ignorance:

"Physics (modern science) is a limited, finite, relative, and partial endeavour, dealing with a very limited aspect of reality. It does not, for example, deal with biological, psychological, economic, literary or historical truths; whereas mysticism deals with all of that, with the Whole".

The context of mysticism in this regard should not only be confined to all the teachings and beliefs concerning life beyond the grave, the soul, spirits and hidden forces in man and divinity (excluding the ordinary and recognised religious teachings) but should be contextualised more in a psychological sense, which connects with the idea of "hidden knowledge" (Ouspensky, 1931, p. 18).

In this context, Ouspensky (1931, pp. 20-28) sees mysticism as the only medium that could break through into our consciousness in what is known as "hidden knowledge". He asserts that life can be seen as two concentric circles of which the outer circle represents humanity in its totality, whereas the inner (esoteric) circle is regarded as a life within life, a mystery, a secret in the life of humanity. The esoteric circle is to be seen as the brain or immortal soul of humanity where all the attainments, all achievements of all cultures and all civilisations are preserved. Ouspensky (1931, p. 30) then claims that this knowledge relates to spheres which have not even been touched upon by science yet. 
However, mankind did not stand still in acquiring this hidden knowledge. It conceptualised this realm through the sciences of religion and art (emotional ways) and through philosophy and science (the intellectual ways) each of which represent similar, equivalent and equally imperfect ways of seeking the truth. Thus, when one views truth at the centre where all four sciences converge, then the nearer (farther) they are to one another the nearer (farther) they are to the truth. Moreover, these sciences not only strengthened their divisions into "academic silos" but also split within themselves through sub-division, into systems, schools, churches and doctrines, consequently denoting their very scientism further and further from the actual truth to a point where these sciences not only contradict each other but also themselves (Ouspensky, 1931, pp. 33-34).

If reality is viewed through the lenses of Oneness as per Quantum Physics and if it manifests itself in the rational as well the non-rational domain and not only through its narrow view of the rational dualistic symbolic representation, then the way social scientists engage to acquire truthful knowledge must change. Hence, the engagement of contemporary research practice must change when one holds a monistic view of reality as per Quantum Mechanics. The paper puts forward such a proposition.

\section{Research Methodology}

The main premise of the paper is to put forward a new engagement with regard to the methodology of scientific research through the metascientific epistemic model of inquiry by addressing the key scientific postulates of truth, objectivity, and rationality of science.

Furthermore, not only do the authors accept that there is an external yet unconscious reality separate from what the scientific community is consciously aware of, but this reality influences how both the social and the natural sciences view the world as a scientific object of inquiry (Bryman et al., 2014, p. 13). Moreover, seeking a new paradigm of engagement which in the end will transform the current status quo of social sciences research practice, the research draws on the paradigms of science as postulated by Thomas Kuhn (Mouton, 2006, pp. 15-16).

Given this abstraction, the authors use theoretical terms and unobservable phenomena to put forward their main argument. The interpretation of this plausible new engagement is thereby argued within the philosophical approach of critical realism of research practice (Bryman et al., 2014, pp. 13, 57-58).

From the above-mentioned, the research methodology can be described as theoretical by nature and follows the metascientific epistemic model of inquiry using a non-experimental conceptual historical inductive research design (Welman, Kruger, \& Mitchell, 2011, pp. 24, 92, 112, 188-190; Bryman et al., 2014, pp. 10-12, $25,96)$.

\section{Limitations of the Study}

Given the methodology followed, the following inherent limitations are to be noted:

Firstly, the availability of data from the stated research design is limited by factors beyond the control of the researcher. In this regard Welman et al. (2011, pp. 190-192) mention that theoretical research is bound by the subjective assessed interpretations of scientists in a certain time-space period it thereby makes it difficult to generalise results. Furthermore, one would expect the reliability and internal validity of theoretical research to be less rigorous as it would be the case with empirical research.

Secondly, the paper assumes a paradigm of non-dualism and thereby engaging academia and researchers who hold similar worldviews. 
Accepting non-dualism as a focal orientation, the research merges the physical and metaphysical domains by drawing primarily on the works of quantum philosopher Peter Ouspensky. Note that the paper does not intend to have a critical discussion of what Ouspensky has put forward nor does it aim to assess various dispositions of other available fusion models. Accepting oneness, the paper concentrates primarily on the consequences of such a possibility.

In the fourth instance, given the nature of the content to be discussed, some literature is of esoteric nature and related fields which are not typical to the academic and scientific engagement. It has a style of its own and is most often written in a very informal manner. Nonetheless, an academic engagement is sought by cross-referencing various non-academic arguments put forward and then contextualising them in the scientific domain as presented in the paper.

The final limitation has to do with the linguistic determinism and linguistic relativity of language, commonly known as the Sapir-Whorf hypothesis. In this regard, linguistic determinism states that "non-verbal thought" does not exist. In essence, thought cannot be "translated" into language as "thought is language" and is therefore completely determined by language itself. This implies that language is not only to be seen as a way of voicing one's ideas, but it is actually the very thing which shapes one's ideas or reality. Also, as reality is perceived and structured by the spoken language, then the real world is to a large extent unconsciously built up on the language habits of cultures. The direct consequence of this is that scientific knowledge is bound to be subjective or relative to one's culture i.e., linguistic relativism (Hussein, 2012, pp. 642-643). Finally, it must be remembered that using language to describe an absolute representation of a non-dual reality is in itself an impossible task. Nonetheless, language stays the only way of communicating the notion of oneness for the time being.

\section{Literature Review}

Given the monistic interpretation of Heisenberg's uncertainty principle, reality can then be contextualised as "One" Mind-only, or Christ-only or Spirit-only, or Energy-only. Although it metaphorically points to a singular absolute Reality it does not imply that it is the "One", a "One" big, powerful and all-knowing "Thing" standing above the universe and omnipotently ruling over it but should rather be seen as a non-dual reality.

\section{Theories of Monism (Non-duality)}

In accepting a non-dual reality as put forward by quantum scientists, religions, mystics, and philosophers alike, one arrives at three different yet interrelated interpretations of one reality as put forward by Eastern and Western worlds: a non-dual reality argued through "All is mind", or acceptance of a physical world as a mere illusion or acknowledgment of a reality as nothing but emptiness.

The interpretation of a reality that is "all emptiness (or energy)" was already mooted in 1911 by quantum physicist Ernest Rutherford who proved in his gold foil experiment that the space occupied by an atom had an estimated radius of $10^{-10} \mathrm{~m}$ compared to that occupied by its nucleus of $10^{-15} \mathrm{~m}$ (Jevremovic, 2009, pp. 25, 28). Arntz, Chasse, and Vicente (2005, p. 64) illustrate this vastness of empty space using the notion of a basketball to reflect the nucleus of a hydrogen atom, then according to Rutherford's postulate, the nearest electron circumventing the nucleus of this atom will be some $32 \mathrm{~km}$ away. The rest will be empty space.

In the spiritual realm, emptiness is also viewed as nothingness or as energy. For instance, the Kaballah as an oral mystical tradition proclaims that life originates from the primal point of nothingness and manifests itself 
through nine stages of the Divine by compacting, condensing and channelling divine energy through the Tree of Life (Andrews, 2007, pp. 12-13, 24-26; Whitehouse, 2007, pp. 8, 46-47, 68). In an alternate interpretation, Buddhism refers to reality as emptiness rather than nothingness to interpret the foundational characteristic of Buddhist doctrine of the "no-self" (Yao, 2010, p. 84).

In the philosophical realm, Martin Heidegger equates the fear of death to the fear of total annihilation which is to be seen as the fear of nothingness (Yao, 2010, pp. 79-80). He asserts that if nothingness or non-being is to be viewed as something outside or separate from being, then reality is to be viewed as a "little island of being in the middle of the great sea of nothingness" (Spade, 1996, p. 124, Heidegger, 1998, pp. 94-95).

The second interpretation sees the physical world as "an illusion or dreamlike state". In explaining his Idealism, Plato uses his cave allegory where he depicts the physical reality as mere shadows cast by puppets against the wall of the cave (Cooper, 1997, pp. 1132-1156).

Monistic gnostic interpretations relating to the illusionistic state of the physical world include the Christian Gnostic text of the Nag Hammadi library which provides an interpretation of Christian mythology before it became "Westernised". The text refers to illusion and enlightenment and sees Jesus as a guide who opens access to a spiritual understanding (Gospel of Thomas, 1984, pp. 301, 307). In the second instance, Hinduism sees Brahman as the only Reality, and views the universe, the world and all else as false by regarding these as mere appearances to man (Sāstrī, 1911, pp. 48, 53). The function of such illusions is explained by Zukav (1990, pp. 206-208, 214-215) who sees the illusion of reality as a learning vehicle and it is like a living picture show which brings forth situations necessary for each soul to experience in order to return to Source through healing.

And finally, "all is Mind" is at the same time viewed by clerical and philosophical interpretations alike. In the first interpretation, the Cloud of Unknowing a mystical text perceives that all thoughts and images and concepts are beneath the metaphorical "cloud of forgetting" and all thinking puts man further from God (Anon, 1922, p. 71). An alternative mystical view comes from Holmes (1998, pp. 28-29, 68, 347) who mentions that in a state of oneness, man will always be within (the mind) of God, hence life cannot be divided against itself. Another esoteric text, A Course of Miracles (2007, p. T554) views God as an abstract Mind, which contains a Thought called Christ. Noting that ideas cannot leave their Source (i.e., God), then Christ's creations can never leave theirs. Contrary to believe, thoughts which are projected out what is seemingly external to the mind, are in fact not outside at all, but rather an effect of what is within.

In a Western philosophical viewpoint, Berkeley reasons that for anything to exist it has to be perceived by the mind. However, as there can be only one mind, i.e., the Mind of God, then according to Berkeley objects do not go out of existence when one is not thinking of them, because God is thinking of these objects all the time, even when unobserved (Wilkins, 2002, pp. 18, 31-32, 55).

When one assumes a monistic view (non-dualistic reality) as put forward by philosophers, mystics and academics alike, then the task at hand is to reconcile both the physical and metaphysical worlds to arrive at a new interpretation of reality of "all is mind". This is done through Ouspensky's six dimensional space-time universe (Seifer, 2008, p. 218).

\section{Ouspensky's Space-time Structure Model}

Accepting the "new physics" of time as put forward by Quantum Mechanics, Ouspensky (1931, pp. 
422-423) questions the measurement of the universe, regarding it as being inadequate and incomplete reasoning with too many things omitted that cannot be measured. The world with all its variety of phenomena does not fit into the 'metageometrical' universe of four coordinates, regardless of how one sees the fourth coordinate (either as a quantity analogous to the first three coordinates, or as an imaginary quantity determining the velocity of light).

Arguing the fourth dimension of space, Ouspensky (1931, pp. 424-427) reasons that all physical and time dimensions evolve in the same way, namely in a cross-sectional manner. For instance, in Figure 1 starting at a point (.) or $\mathrm{d}^{0}$, i.e., zero dimension, the perpendicular direction (or its rotation in the curved space of time) to itself and leaving a trace of its movement will form a line $\left(\mathrm{d}^{1}\right)$, and the perpendicular direction of the line to itself becomes a plane or $\mathrm{d}^{2}$ whereas the perpendicular direction away from the plane becomes a three-dimensional solid $\left(d^{3}\right)$. He furthermore deduces the rule that if there are three dimensions $\left(d^{3}\right)$, a two-dimensional real body cannot exist by itself and when taken separately, would be an imaginary figure - a mere section of a body of three dimensions.

Furthermore, it is also clear that the solid of space $\left(\mathrm{d}^{3}\right)$ is not sufficient for the description of the universe as any motion will immediately destroy the $\mathrm{d}^{3}$ universe. Hence, a fourth coordinate which takes time into consideration and allows for motion in the fourth time-space dimension $\left(\mathrm{d}^{4}\right)$ has to be considered.

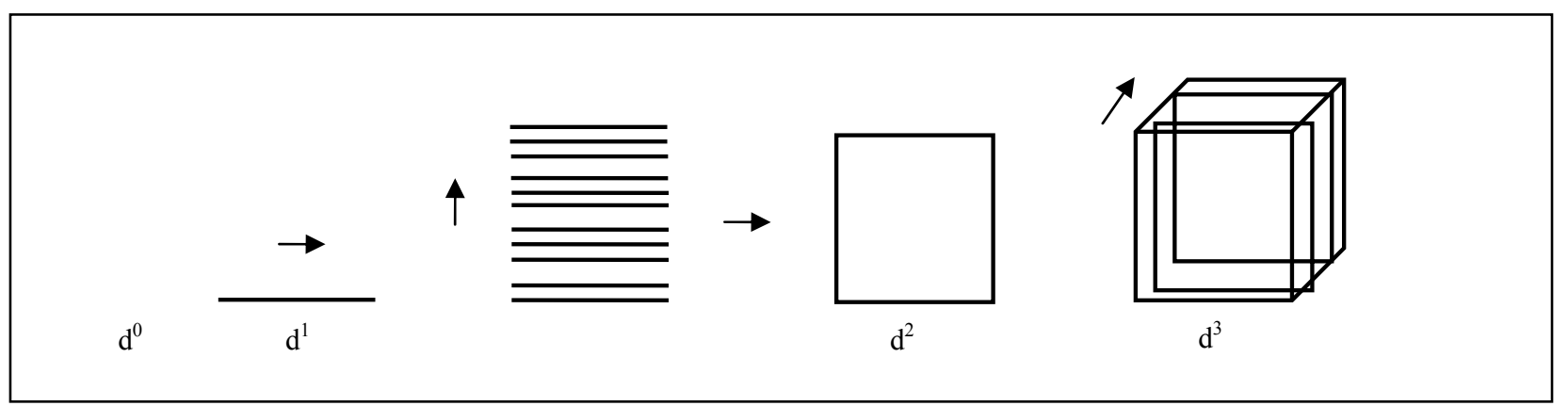

Figure 1. Solid of space defined (Source: Ouspensky (1931, p. 424) and Seifer (2008, pp. 229-230)).

Motion according to Ouspensky (1931, p. 425) is expressed in three dimensions, namely duration, velocity and "direction". Yet, direction does not lie in Euclidean space. Instead, it is a direction from before to after, never changing nor disappearing. Time is a measurement of motion, and if represented by a line, would represent a spiral, i.e., a three-dimensional line with three coordinates. The three-dimensionality of time according to Ouspensky (1931, p. 425) is completely analogous to the three-dimensionality of space. As with time, space is not measured by cubes but linearly in different directions as per Figure 1. However, the curvature of time is actually only determined by two spatial coordinates, namely duration and velocity. The third coordinate "direction" is not a quantity but rather an absolute condition. Hence, the fourth coordinate is insufficient to describe time, making the curvature of the spiral undefined. What is required for the construction and designation of time is to unite all three coordinates of time into one whole, which then will give an adequate description of time (represented by a spiral). This, according to Ouspensky, points to the presence of (an)other space-time dimension(s). What is then proposed is the continuation of the three dimensions of space $\left(d^{3}\right)$ into additional three dimensions of time $\left(\mathrm{d}^{4}, \mathrm{~d}^{5}\right.$ and $\left.\mathrm{d}^{6}\right)$.

Arguing the fourth dimension $\left(\mathrm{d}^{4}\right)$, Ouspensky (1931, pp. 79-80, 90-92, 424) reasons that for a three-dimensional real body to exist, one must recognise the existence of a fourth dimension of space $\left(\mathrm{d}^{4}\right)$, for if 
man only possesses three dimensional capabilities, he would not exist at all because the solid of space $\left(\mathrm{d}^{3}\right)$ can only be observed from a figure of a higher dimension $\left(d^{4}\right)$.

Using the mind as focal point, Ouspensky (1931, pp. 426-427) integrates it with the structure of the four-dimensional space-time continuum. He argues that for a three-dimensional cube as in Figure 2 to exist in a time continuum, it has to be projected by the mind along the past-present-future timeline (fourth dimension). Viewing the imaginary line in Figure 2 by the three points "before", "now" and "after" as the "horizontal time" of man's section of existence, Ouspensky furthermore argues that everything known, felt and recognised by man lies on this imaginary line-regardless of the time frame. To speculate the whereabouts of the three-dimensional cube in the future as per Figure 2, one has to project the imagined cube into an array of possible "places" within the mind which according to Seifer (2008, p. 219) allows one to enter a realm that is not part of the physical space-time continuum, but instead travels with it.

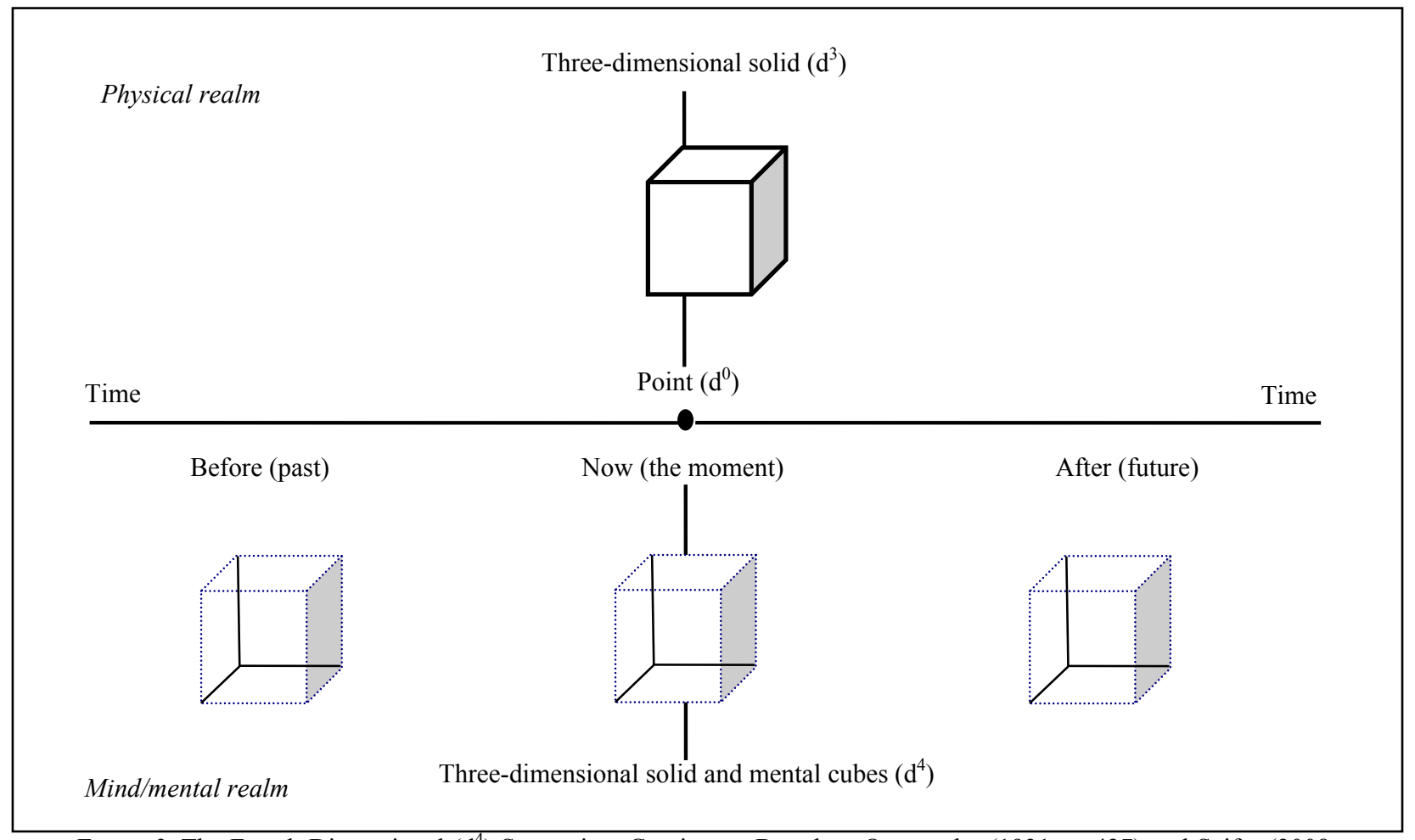

Figure 2. The Fourth Dimensional $\left(\mathrm{d}^{4}\right)$ Space-time Continuum Based on Ouspensky (1931, p. 427) and Seifer (2008, pp. 219, 243).

Ouspensky's imminent conclusion is that the fourth dimension is the dimension of the mind and would be synonymous with the term hyperspace or inner space:

"The psychic (mind), as opposed to the physical or the three-dimensional, is very similar to what should exist in the fourth dimension... No obstacles or distances exist for it. It penetrates impenetrable objects, visualises the structure of atoms, calculates the chemical composition of stars, studies life on the bottom of the ocean, the customs and institutions of a race that disappeared tens of thousands of years ago... No walls, no physical conditions, restrain our fantasy, our imagination" (Ouspensky, 1993, p. 95)

Using the fourth dimension line (as per Figure 2) which is determined by three points "before", "present", "after", Ouspensky (1931, pp. 424-425) argues that the fifth dimension runs perpendicular to this line of time. He 
then draws several lines perpendicular to the fourth dimensional line (before-now—after). These represent the perpetual existence of past and possible future moments as per Figure 3. Each of these perpendicular lines represents the perpetual now for some moment, and every moment has such a line of perpetual now, and by connecting all the vertical lines forms the fifth dimension (Ouspensky, 1931, pp. 426-427).

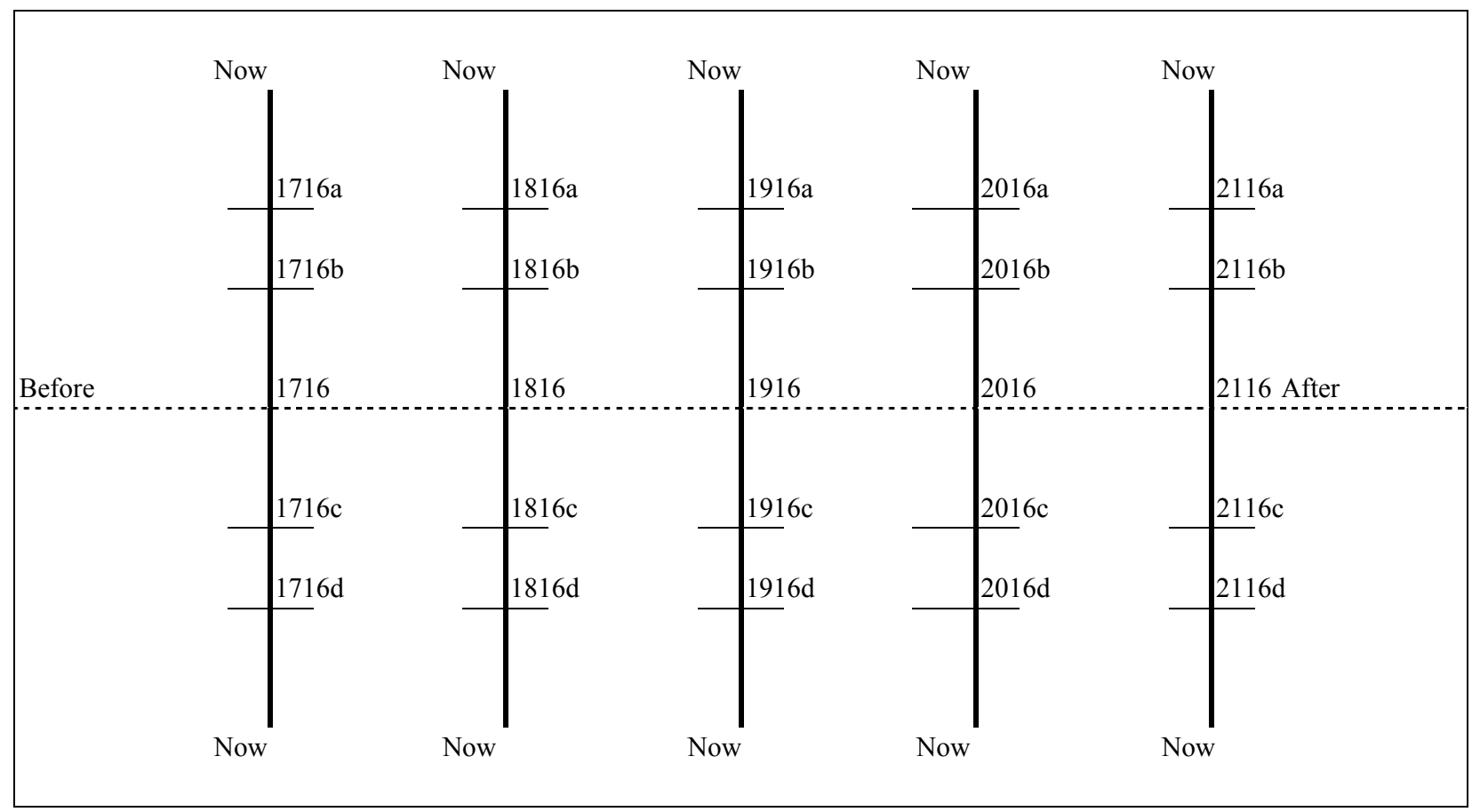

Figure 3. Ouspensky's Fifth Dimension (d ${ }^{5}$ ) (Source: Ouspensky, 1931, p. 425).

Therefore the perpendicular direction away from the fourth dimension of space will form what is called a hypercube (Figure 4), which makes provision for the inclusion of the solid of space $\left(\mathrm{d}^{3}\right)$ as well the mental inner (hyper or mind) space of reality. The latter according to Seifer (2008, p. 234) can be seen to be compatible with Freud's idea of the libido. It is to be viewed as the mental plane of existence lying beneath the physical space-time environment and includes the structured hierarchic level of the inner mind which encompasses the entire Freudian/Jungian model of a consciousness, preconsciousness, unconsciousness, and the collective unconsciousness.

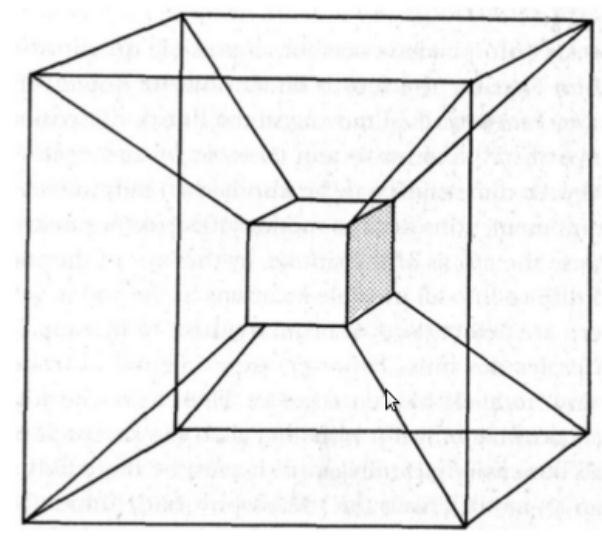

Figure 4. The Fourth Dimension of Space $\left(\mathrm{d}^{4}\right)$ - the Hypercube. 
Ouspensky (1931, pp. 425-426) continues that each moment of the "now" on the line of time (represented by one of the parallel lines), say the 1st of January 2016, contains a number of varying possibilities. However, the number of possibilities contained in every moment must necessarily be limited by the conditions of being or physical existence, for if they were not, then any impossibility of reality would not exist. This is what Ouspensky (1931, p. 418) refers to as the line of actualisation, which will be the line of the fourth dimension - the line of time. Thus, the perpetual existence of this actualisation, being the line perpendicular to the line of time, will be the line of the fifth dimension or the line of eternity.

The fifth dimension could also be seen as the fourth dimension in infinite repetition, which corresponds to "superposition" of Quantum Physics in which, prior to measurement, a quantum system can be in any or in all possible states simultaneously forever. This is illustrated by Schrödinger's hypothetical cat experiment in which a cat oscillates between two states (life and death) in a sealed lead box. These states can be seen as mere possibilities and are regarded to be in superposition with one another representing the wave-function as per Heisenberg. This wave function then collapses into a definite, single state, i.e., particles once being consciously observed in which its fate (being dead or alive) is decided (Carpenter \& Anderson, 2006, p. 46; Monroe, Meekhof, King, \& Wineland, 1996, pp. 1131-1132).

All the possibilities that have been created or have originated in the world must be actualised which leads him to believe that the sixth dimension of space is the line of the actualisation of all possibilities in the fifth dimension (Ouspensky, 1931, p. 427).

"The line of time, repeated infinitely in eternity, leaves at every point unactualised possibilities. But these possibilities, which have not been actualised in one time, are actualised in the sixth dimension, which is the aggregate of 'all times'. The lines of the fifth dimension, which run perpendicular to the line of 'time', form as it were a surface".

Hence, every line of the sixth dimension starts from every point in all possible directions, i.e., from a (time) plane to a (time) cube so to speak to form a solid or three-dimensional continuum of time, and includes in itself all the possibilities. It would encompass the probable futures "off" the probable futures of the fifth dimension and will encompass all and everything (Seifer, 2008, p. 240). The number of dimensions Ouspensky (1931, p. 424) limits to six because in the property of the sixth dimension includes in itself all possibilities of the given scale.

\section{Precognition}

The realm of inner space lies beneath the surface of the physical reality and its makeup is structured quite differently yet in a lawful way from three-dimensional space. In this regard, future probabilities play out in the multidimensional realm of the mind and at times they also manifest on the plane of the physical reality and in various time dimensions what Deutsch (2001, p. 20) refers to as the multiverse of reality. Therefore, the totality of the hyperspace permeates all levels of physical space at all times at once which can then be referred to the (all encompassing) realm of the Mind of God (Seifer, 2008, p. 236).

With reference to Ouspensky's works Seifer (2008, p. 238) reasons all future probabilities exist in the second dimension of time, and asserts that this dimension is compatible with theories about precognition: a state where all events that are more or less likely to occur in the future are cognised before they actually become manifested in the fourth dimension of space, i.e., the present now. Several concepts relate to precognition as shown in (but not limited to) Table 1. 
Table 1

Precognition Conceptualised

\begin{tabular}{|l|l|l|l|l|}
\hline Acausal & Déjà vu & God's Will & Predetermination & Synchronicity \\
\hline Astrology & Destiny & I Ching & Prediction & Tarot \\
\hline Asymmetrical time & Divination & Indeterminacy & Probable futures & Teleology \\
\hline Backward causation & Entelechy & Omen & Prophecy & Telepathy \\
\hline Backward time & Fate & Oracle & Prophet & Time symmetry \\
\hline Causality & Forecasting & Palmistry & Reincarnation & Preordained \\
\hline Clairvoyance & Foreknowledge & Periodicity & Seer & Premonition \\
\hline Cycles & Geomancy & Predestined & Space-time & Foretelling \\
\hline
\end{tabular}

Source: Seifer (2008, p. 208).

Having established the link between precognition and the fifth dimension, the authors conclude by proposing a new research design to be considered when researching the fifth space-time dimension (and beyond).

\section{Conclusion}

By engaging in science, academics in the social sciences have at their disposal three research strategies, namely the exploratory, descriptive and causal research designs. Yet, all of these research designs gather evidence through the narrow spectrum of the conscious rational observable reality which is not appropriate researching the fifth dimension by default. Thus, in order to attain truthful knowledge in the realm of science through the postulate of oneness, the unconscious, unobserved and non-manifested reality in the fifth dimension needs to be included. In this regard, an additional research design namely "the metaphysical research design" which incorporates all aspects of precognition is put forward for consideration.

Relating to the concepts of precognition as postulated by Seifer $(2008$, p. 208) in Table 1, the metaphysical research design contextualised in a research framework with the appropriate research methods (not exclusively) may then look as follows (see Table 2).

Considering the key properties of the metaphysical research design as put forward in Table 2, the new proposed design should not actually be seen as a substitute but rather as an extension of the current three research designs in the fourth dimension of space and thereby providing a more holistic engagement. Thus, making the metaphysical research design available to the sciences, one can assume that the future engagement of research practice will see a shift from the physical to the metaphysical domain, matter to energy, materialism to mentalism, invert universe (or reality) to an evolving, conscious universe (Edwards, 2006, p. 46). These shifts are to be seen as the building blocks of future research practice, including the (remote) possibility that the new proposed design could even serve as the portal into the third dimension of time (if it can be researched at all).

Coming back to the research problem posed, the metaphysical research design addresses all three notions put forward in the problem statement. Firstly, as the new research paradigm investigates the unmanifested (or irrational) reality in conjunction with the "rational" reality of science, it makes scientific knowledge more truthful and inclusive. In the context of Quantum Mechanics as per Heisenberg, it allows for an investigation into the "wavelike" (fifth dimension) and "particle like" (fourth dimension) realities of the universe. Thus, by including both realities, it addresses the initial issue of overemphasis of rationalism of scientific research and allows for a more balanced and holistic view of reality. 
Secondly, incorporating the unmanifested reality in the search for truth allows what Wilber (1993, pp. 70, 89) refers to as the "absolute subjectivity" to replace the concept of objectivity of science. Wilber sees the collective dualism as having emerged from an evolutionary process "out of" the infinite, i.e., the absolute subjectivity over time through four consecutive splits. Hence, in the illusionary dualistic nature of symbolic perceptions of past vs. future, subject vs. object, etc., then the discussion of a Mind-only reality is not to be seen as an analytical prescription of how things should be, but rather provides a metaphorical description of a state of affairs that already exists. Absolute subjectivity knows the universe simultaneously, i.e., as a solid of time and space and not in a sequence of time through a distance called space. It is a reality that cannot be engineered in some future or looked at backwards but is to be understood as a present fact (Wilber, 1993, p. 90). It includes both the infinite (spaceless) and eternal (timeless) and is to be seen as the Witness or Ultimate Seer within each of us, a mere reality of one's inner God's centre.

Finally, the engagement of the fifth dimension of space-time should not only be limited to seeing future probabilities through research processes, but should also include the specific body of knowledge of the "esoteric sciences" as a research product. Hence, it calls for enlarging the current body of knowledge by adding all "hidden knowledge" within the esoteric realm to the sciences and thereby making it all encompassing and inclusive.

In concluding, by taking a proactive stance it is recommended that the academic research fraternity embrace what is being put forward here, and allow future researchers and scientists to engage in the unmanifested domain of reality. The nullifying of Classical-Newton physics postulated by Quantum Mechanics serves as a grim reminder that this can (or will) spill over into the social sciences, including the sciences of psychology. Ignoring it, the research fraternity does so at its own peril.

Table 2

The Metaphysical Research Design

\begin{tabular}{|c|c|c|}
\hline \multirow{2}{*}{ Conceptualisation } & Research philosophy: & Realism and interpretivistic approaches. \\
\hline & Research discourse: & Abductive reasoning. \\
\hline \multirow{3}{*}{ Data collection } & \multirow{3}{*}{$\begin{array}{l}\text { Research techniques } \\
\& \text { methods: }\end{array}$} & $\begin{array}{l}\text { Natural phenomena: } \\
\text { Divination systems: Astrology. }\end{array}$ \\
\hline & & $\begin{array}{l}\text { Human-related natural phenomena: } \\
\text { Divination by numbers: Numerology. } \\
\text { Pendulum dowsing. } \\
\text { Divination by names: Onomancy. } \\
\text { Divination by inspection Chiromancy (palmistry), Pedomancy, leaf divination. } \\
\text { Divination by dreams: Oneiromancy. } \\
\text { Telepathy. } \\
\text { Geomancy: Feng Shui. }\end{array}$ \\
\hline & & $\begin{array}{l}\text { Man-made natural voluntary phenomena } \\
\text { Necromancy: Clairvoyance, channelling, mediums, seers, telepathy, crystal balls, } \\
\text { extra sensory perception and past life regressions. } \\
\text { Divination by Sortilege: } \\
\text { Casting: Rune casting, crystal and tree divinations. } \\
\text { Selection: The I Ching, oracle cards, e.g., the Tarot, Zen \& Angel. } \\
\text { Spontaneous divination: } \\
\text { Bibliomancy: prophecy and aura readings. }\end{array}$ \\
\hline
\end{tabular}

Source: Eason (2003, pp. 13-14, 81-82, 133, 164-165, 183-184, 218, 243-244, 262-263, 275-276) ; Yalsovac (2005, pp. 3, 5-6, 8, $10,14-15,19,22,41,50,61-71)$. 


\section{References}

Anon. (1922). A cloud of unknowing (2nd ed.). London: Watkins.

Andrews, T. (2007). Secret doors of the Qabala. Jackson: Dragonhawk.

Arévalo Aguilar, L. M. García Quijas, C. P. and Robledo-Sanchez, C. (2013). The improvement of the Heisenberg uncertainty principle, in Advances in Quantum Mechanics. Bracken (ed). London: InTech. Retrieved from http://www.intechopen.com/ books/advances-in-quantum-mechanics/the-improvement-of-the-heisenberg-uncertainty-principle

Arntz, W., Chasse, B., \& Vicente, M. (2005). What the bleep do we know? Deerfield Beach: Health Communication.

Babbie, E., \& Mouton, L. (2009). The practice of social research. Cape Town: Oxford University Press.

Bless, C., Higson-Smith, C., \& Kagee, A. (2008). Fundamentals of social research methods-An African perspective (4th ed.). Cape Town: Juta's.

Boikess, R. S., \& Edelson, E. (1978). Chemical principles. New York: Harper \& Row.

Bryman, A., Bell, E., Hischsohn, P., dos Santos, A., du Toit, J., Masenge, A., van Aardt, I., \& Wagner, C. (2014). Research methodology: Business and management contexts. Cape Town: Oxford University Press.

Carpenter, R. H. S., \& Anderson, A. J. (2006). The death of Schrödinger's cat and of consciousness based quantum wave-function collapse. Annales de la Fondation Louis de Broglie, 31(1), 45-52.

Cooper, J. M. (ed.). (1997). Plato complete works-Republic VI. Indianapolis: Hackett.

Course in Miracles, A. (2007). Text, workbook for students, and manual for teachers-combined volume: Foundation for inner peace (3rd ed.). London: Penguin Group.

Deutsch, D. (2001). The structure of the multiverse. Centre for Quantum Computation. University of Oxford. April.

Eason, C. (2003). The complete guide to divination: How to foretell the future using the most popular methods of prediction. London: Judy Piatkus.

Edwards, G. (2006). Living magically: A new vision of reality. London: Piatkus Books.

Garbers, J. G. (ed.). (1996). Effective research in the human sciences. Pretoria: Van Schaik.

Gospel of Thomas. (1984). In W. Barnstone (Ed.), The other bible: Ancient alternative scriptures. New York: HarperCollins.

Heidegger, M. (1998). Patmarks. McNeill, W. (Ed.). New York: Cambridge University Press.

Hilgevoord, J., \& Uffink, J. (2006). The uncertainty principle. In E. N. Zalta (Ed.) (Spring 2014). Stanford Encyclopaedia of Philosophy. Stanford: The Metaphysics Research Lab. Retrieved from http://plato.stanford.edu/archives/spr2014/entries/qt-uncertainty

Holmes, E. (1998). The science of mind: A philosophy, a faith, a way of life. New York: Penguin Putnam.

Hussein, B. A. S. (2012). The Sapir-Whorf hypothesis today. Theory and Practice in Language Studies, 2(3), 642-646.

Jevremovic, T. (2009). Nuclear principles in engineering. New York: Springer.

Monroe, C., Meekhof, D. M., King, B. E., \& Wineland, D. J. (1996). A "Schrödinger cat" superposition state of an atom. Science, $272,1131-1132$

Mouton, J. (2006). Understanding social research (2nd ed.). Pretoria: Van Schaik.

Ouspensky, P. D. (1931). A new model of the universe: Principles of the psychological method in its application to problems of science, religion and art. New York: Alfred A. Knoff.

Sāstrī, P. D. (1911). The doctrine of Māyā. London: Luzac.

Seifer, M. S. (2008). Transcending the speed of light-Consciousness, quantum physics, and the fifth dimension. Vermont: Inner Traditions.

Spade, P. V. (1996). Jean-Paul Sartre's being and nothingness. Course material: Indiana.

Welman, C., Kruger, F., \& Mitchell, B. (2011). Research methodology (3rd ed.). Oxford University Press.

Whitehouse, M. (2007). Understanding the mysteries of Kabbalah: Exploring the ancient esoteric heart of Jewish mysticism. London: Hermes House.

Wilber, K. (1993). The spectrum of consciousness (2nd ed.). Wheaton: Theosophical.

Wilber, K. (2000). Grace and grit-Spirituality and healing in the life and death of Treya Killam Wilber (2nd ed.). Boston: Shambhala.

Wilkens, D. R. (Ed.). (2002). A treatise concerning the principles of human knowledge. George Berkeley, London: Jacob Thonson.

Yalsovac. N. (2005). Divination systems. Retrieved 21 September, 2015, from http://www.umsonline.org/PrinterFriendly/DivinationSystems.pdf.

Yao, Z. (2010). Typology of nothing: Heidegger, Daoism and Buddhism. Comparative Philosophy, 1(1).

Zukav, G. (1990). The seat of the soul—An inspiring vision of humanity's spiritual destiny. London: Rider. 